\title{
Parameterization of net radiation in an arid city of northwestern Mexico
}

\author{
RAFAEL GARCÍA CUETO, NÉSTOR SANTILLÁN SOTO, ZALIA HARO RINCÓN and SARA OJEDA \\ BENÍTEZ \\ Instituto de Ingeniería, Universidad Autónoma de Baja California, Boulevard Benito Juárez y C. de la Normal, \\ Col. Insurgentes Este, 21280 Mexicali, Baja California, México \\ Corresponding author: Rafael García Cueto; e-mail: rafaelcueto@uabc.edu.mx
}

\begin{abstract}
GONZALO BOJÓRQUEZ MORALES
Facultad de Arquitectura, Universidad Autónoma de Baja California, Boulevard Benito Juárez y C. de la Normal, Col. Insurgentes Este, 21280 Mexicali, Baja California, México
\end{abstract}

Received September 8, 2014; accepted January 28, 2015

\begin{abstract}
RESUMEN
La urbanización, al cambiar las propiedades de la superficie, modifica de manera sensible el balance de radiación y con ello el clima citadino, por lo que se propuso cuantificar ese balance en diferentes coberturas superficiales para varios días del mes de agosto de 2011 en una ciudad árida del noroeste de México. Se estimó el albedo de cada superficie y algunas otras propiedades de la atmósfera local, como el índice de claridad atmosférica $\left(K_{0}\right)$ y la emisividad atmosférica $\left(\varepsilon_{a t m}\right)$. Las superficies en las que se realizaron las mediciones fueron asfalto, concreto, poliestireno con pintura elastomérica blanca (PPEB), arcilla y césped. Se encontró que para un ciclo de $24 \mathrm{~h}$ de medición, el mayor valor promedio de radiación neta fue para el asfalto $\left(146.1 \mathrm{Wm}^{-2}\right)$, y el menor valor promedio para el PPEB $\left(33.6 \mathrm{Wm}^{-2}\right)$. Los valores estimados de albedo varían de acuerdo con la superficie, mientras que los de $K_{0}$ y $\varepsilon_{a t m}$ dependen de las condiciones atmosféricas prevalentes. A partir de las mediciones se propusieron modelos estadísticos preliminares de la radiación neta en función de la radiación solar entrante y la radiación neta de onda corta, encontrándose en todos los casos coeficientes de determinación superiores a 0.97 . Se analizan las probables implicaciones de los resultados encontrados en el medio urbanizado.
\end{abstract}

\begin{abstract}
During the process of urbanization, different surface properties significantly alter the radiation balance. This paper attempts to quantify this balance over different surface types in an arid city of northwest Mexico over several days in August 2011. The albedo of each surface type, as well as local atmospheric properties such as the atmospheric clearness index $\left(K_{0}\right)$ and atmospheric emissivity $\left(\varepsilon_{a t m}\right)$, were estimated. The surfaces on which measurements were performed were asphalt, concrete, polystyrene painted with white elastomeric paint (PWEP), clay, and grass. It was found that, for a 24-h cycle of measurement, the highest average value of net radiation was for asphalt $\left(146.1 \mathrm{Wm}^{-2}\right)$, and the lowest average value was for PWEP $\left(33.6 \mathrm{Wm}^{-2}\right)$. Estimates of albedo values vary depending on the surface, whereas $K_{0}$ and $\varepsilon_{a t m}$ are dependent on prevailing atmospheric conditions. From these measurements, preliminary statistical models of net radiation as a function of incoming solar radiation and net shortwave radiation were proposed. For each model, the coefficients of determination were higher than 0.97 . We discuss the likely implications of the results found for the urban planning of the city.
\end{abstract}

Keywords: Radiation balance, net radiation, shortwave radiation, longwave radiation, albedo, atmospheric emissivity, atmospheric clearness index. 


\section{Introduction}

Net radiation is a fundamental driver of climate in the lower layers of the atmosphere, and its effects depend on both the structure and composition of the atmosphere and the presence of clouds, in addition to surface characteristics such as albedo, emissivity, temperature, moisture and the thermal properties of underlying soil (Kessler and Jaeger, 1999). It is also the driving force for many physical, dynamic, and biological processes, including warming of the soil and air, photosynthesis, and evapotranspiration, the latter being important for the quality and yield of crops and the planning of water resources (Bennie et al., 2008; Ji et al., 2009; Li et al., 2009; Geraldo-Ferreira et al., 2011; Ayoola, 2014).

Net radiation is also important in studies of surface energy balance, where its magnitude is mainly related to sensible and latent heat flux (Kalthoff et al., 2006). The relationship between radiation and surface energy balance is important for understanding urban climates (or microclimates) caused by varying surface types (Arnfield, 2003). The spatial heterogeneity of urban landscapes leads to a non-uniform transmission and distribution of energy radiation. Because the urban area is a complex physical interface, the thermodynamic and kinetic properties of the underlying surface may be substantially changed by modifying the physical characteristics of that surface (Wang and Gong, 2010; Cui et al., 2012). These factors result in cities that have unique climatic characteristics.

Many previous studies have examined rural-urban radiation differences using climate models, models of terrestrial ecosystems, or computational fluid dynamics models. However, these studies have combined the radiation differences produced by the heterogeneity of the urban landscape, making it difficult to explain the energy transformation from different surfaces and to accurately simulate micro-climatic characteristics within a city (Groleau and Mestayer, 2013). In addition, due to the variety of factors involved, observations from weather stations cannot effectively distinguish the effects of underlying surfaces on components of the radiation balance (White et al., 1978; Christen and Vogt, 2004). Despite its importance, net radiation is measured at a limited number of standard meteorological stations because net radiometers are expensive instruments and require constant care in the field. Therefore, to gain a better understanding of the effects that different horizontal surfaces have on radiation balance and the subsequent effect on the surrounding environment, an experimental campaign was conducted in Mexicali, an arid city in northwest Mexico, on five different surface materials. Using measurements gathered from this study, we postulated preliminary statistical models of net radiation as a function of incoming solar radiation and net shortwave radiation, as well as estimates of biophysical characteristics such as albedo, atmospheric clearness index, and atmospheric emissivity. The implications of the results on urban planning are discussed.

\section{Methodology}

In the following section, we discuss the procedures and materials used during this study, including the experiment site and its construction, mathematical models used to estimate biophysical properties, and the theoretical background regarding net radiation models.

\subsection{Experimental campaign}

The experiments were conducted at the Engineering Institute of the Autonomous University of Baja California, located on a campus in Mexicali, Mexico $\left(32.6^{\circ} \mathrm{N}, 115.5^{\circ} \mathrm{W}, 12\right.$ masl). Mexicali has a dry, arid climate with extremely hot summers and cold winters and is one of the hottest cities in Mexico, with average maximum temperatures in August of $42{ }^{\circ} \mathrm{C}$. Mexicali receives $90 \%$ of the maximum potential hours of daylight each year and a mean annual rainfall of approximately $75 \mathrm{~mm}$ (García-Cueto and Santillán-Soto, 2012).

Radiation balance data and weather information were collected by the staff of Applied Climatology. Observation equipment was installed on the roof of the Engineering Institute. The study area contained mixed-use land, but the experimental design allowed us to measure the relevance of each surface. A wooden drawer with dimensions of $1 \times 1 \times 0.55 \mathrm{~m}$ was placed on a platform $1.5 \mathrm{~m}$ away from the roof of the building. The drawer was pre-filled with native soil and overlaid with the following surfaces: asphalt, concrete, polystyrene with white elastomeric paint (PWEP), clay, and grass. At a height of $0.20 \mathrm{~m}$ from each surface, an NR01 radiometer (Hukseflux Thermal Sensors), which measures four components 


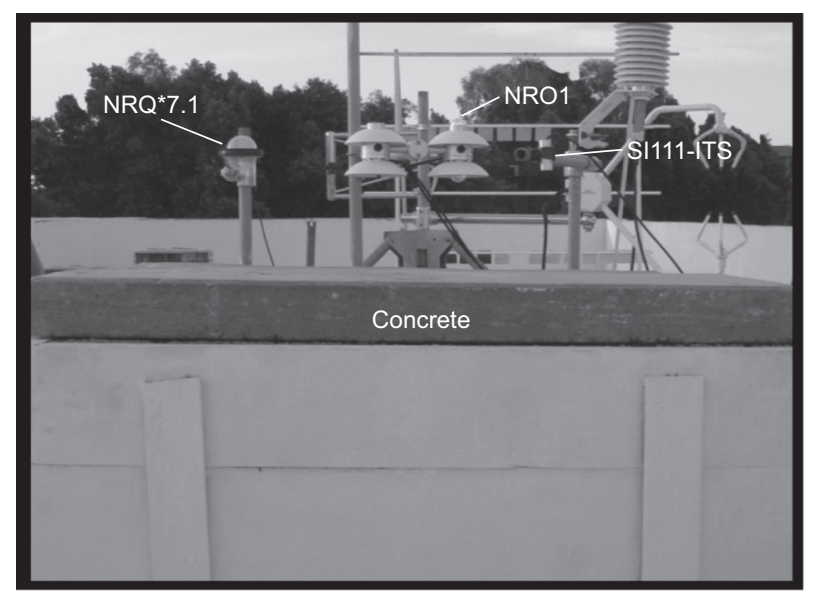

Fig. 1. Experimental setup with concrete surface as an example, with the radiometers (NR01 and NRQ*7.1) and infrared thermometer (SI111-ITS) used in the measuring campaign.

of the radiation balance, was installed (Fig. 1). The purpose of installing the NR01 radiometer at this height $(0.20 \mathrm{~m})$ was so that the lower surface of this instrument could "see" the underlying surface practically without interferences due to the presence of other nearby obstacles. This is because the radiative transfer is governed by the geometry of a surface radiation measurement (i.e., the upwelling part and reflected part of a net radiation measurement) and can be expressed in terms of measurement height and radial separation from the nadir point of the measurement (Schmid, 1997). The radiation source area, or view factor, of the lower surface of the NR01 radiometer was estimated accordingly with Anthoni et al. (2000) as:

$R_{\max }=z \tan 85^{\circ}$

$R_{\max }$ refers to the maximum radius that is sufficient to capture $99 \%$ of the upwelling radiation contributions, and $z$ is the measurement height $(\mathrm{z}=0.20 \mathrm{~m})$. The estimation of $R_{\max }$ with Eq. (1) gave a value of $2.3 \mathrm{~m}$, which corresponds to the field of view of the lower surface of the NR01 radiometer.

Another net radiometer, an NRQ*7.1 model by Radiation and Energy Balance Systems (REBS), Seattle, WA, was installed at the same height $(z=$ $0.20 \mathrm{~m}$ ) to compare the measures realized with the NR01 radiometer. Each surface was measured for a full 24-h cycle over several days in August 2011, which is one of the warmest months in this part of
Mexico, and so far there have not been replicas of these measurements in other months of the year. The temperature of each surface was measured with an SI-111 infrared temperature sensor (SI111-ITS, Campbell Sci.) that provides a non-contact means for measuring the surface temperature of an object. It senses the infrared radiation being emitted by the target with an absolute accuracy of $\pm 0.2{ }^{\circ} \mathrm{C}$ in the range of -10 to $65^{\circ} \mathrm{C}$, and its response time to changes in the target temperature is less than $1 \mathrm{~s}$.

\subsection{Radiation balance}

The energy balance components were measured and the partial net all-wave radiation parameterization (NARP) utilization scheme over all surface types (Offerle et al., 2003) was employed. The radiation budget for a horizontal surface, called net radiation, is given in $\mathrm{Wm}^{-2}$ and was estimated by Eq. (2). The net radiation $Q^{*}$ is due to the difference between downwelling shortwave radiation $(K \downarrow)$, reflected shortwave radiation $(K \uparrow)$, downwelling longwave radiation $(L \downarrow)$ and upwelling longwave radiation $(L \uparrow)$. The net shortwave flux depends on the incident solar radiation $K \downarrow$ and on the surface albedo $\alpha$. The net longwave flux depends upon the downwelling longwave radiation $L \downarrow$, surface emissivity $\varepsilon_{s}$, and radiating temperature $T_{s}$ :

$$
\begin{aligned}
& Q^{*}=K \downarrow-K \uparrow+L \downarrow-L \uparrow \\
& =(1-\alpha) K \downarrow+L \downarrow-\left\{\left(1-\varepsilon_{s}\right) L \downarrow+\varepsilon_{s} \sigma T_{s}^{4}\right\} \\
& =(1-\alpha) K \downarrow+\varepsilon_{s}\left(L \downarrow-\sigma T_{s}^{4}\right)
\end{aligned}
$$

The surface characteristics critically influence $Q^{*}$. In the previous equation, $\sigma_{s}$ refers to the Stefan-Boltzmann constant $\left(\sigma=5.67 \times 10^{-8} \mathrm{Wm}^{-2} \mathrm{~K}^{-4}\right)$. Radiative components were measured with the NR01 radiometer performing separate measurements of solar radiation (shortwave) and far infrared (long wavelength). The spectral response of the shortwave radiometer (pyranometer) is $300-2800 \mathrm{~nm}$, and it has a sensitivity of $10-40 \mu \mathrm{V} / \mathrm{Wm}^{-2}$ and a field of view of $180^{\circ}$. It is a second-class pyranometer according to the World Meteorological Organization and ISO classification system (ISO 9060). The longwave radiometer (pyrgeometer) has a spectral response of $4500-50000 \mathrm{~nm}$ as well as a field of view of $180^{\circ}$ with a sensitivity of $5-15 \mu \mathrm{V} / \mathrm{Wm}^{-2}$. Care was taken in the installation of the instrument to prevent shadows of trees, buildings, and other structures from interfering. 


\subsection{Estimation of biophysical properties}

\subsubsection{Albedo $(\alpha)$}

The albedo $(\alpha)$ is defined as the ratio of reflected radiation $(K \uparrow)$ to downwelling radiation $(K \downarrow)$, both shortwave, at a specific angle of incidence:

$\alpha=K \uparrow / K \downarrow$

\subsubsection{Atmospheric emissivity $\left(\varepsilon_{\text {atm }}\right)$}

The atmospheric emissivity $\left(\varepsilon_{a t m}\right)$ is a measure of the efficiency at which an object emits radiation relative to a perfect emitter (a blackbody); $\varepsilon_{a t m}$ was obtained from measurements of downwelling longwave radiation $(L \downarrow)$ and air temperature $(T)$, using the Stefan-Boltzmann constant:

$\varepsilon_{a t m}=L \downarrow / \sigma_{s} T^{4}$

\subsubsection{Atmospheric clearness index $\left(K_{0}\right)$}

The atmospheric clearness index $\left(K_{0}\right)$ gives a measure of the atmospheric effects at a place on the insolation. The clearness index is a stochastic parameter, which is a function of time of year, season, climatic condition, and geographic location (Kumar and Umanand, 2005). This index allows for the estimation of the amount of energy dissipated and transformed into different processes by solar radiation and is physically associated with the path of radiation through the atmosphere to the surface, whether it be level land or sea. $K_{0}$ was obtained by the expression proposed by Colliber (1991):

$K_{0}=K \downarrow / Q_{\text {ext }}$

where $Q_{\text {ext }}$ refers to extra-terrestrial daily solar radiation (Iqbal, 1983), which was obtained by:

$$
\begin{aligned}
& Q_{\text {ext }}=(24 / \Pi) I_{s c} \xi_{0}(\Pi / 180) \omega_{s}(\sin \delta \sin \varphi) \\
& +\left(\cos \delta \cos \varphi \sin \omega_{s}\right)
\end{aligned}
$$

where $I_{s c}$ is the solar constant $=1367 \mathrm{Wm}^{-2}, \xi_{0}$ is the eccentricity correction factor for the mean EarthSun distance, $\delta$ is the declination of the sun, $\varphi$ is the latitude of the city of Mexicali $\left(32.6^{\circ}\right)$, and $\omega_{s}$ is the hour angle of sunrise. The following expressions were used to calculate $\delta, \xi_{0}$ and $\omega_{s}$ :

$\delta=(23.45 * \Pi) / 180)(\sin [2 \Pi(d j+284) / 365]) ;$

$d j$ is the Julian day $\xi_{0}=1+0.033 \cos (2 \Pi d j / 365)$

$\omega_{s}=-\cos ^{-1}(-\tan \delta \tan \varphi)$

2.3.4 Proposal of preliminary net radiation models

Two types of models were proposed, the first based on the incoming solar radiation for each type of experimental surface and the second in terms of net shortwave radiation. The first type of model is a linear regression, as set forth below:

$Q^{*}=\left(b_{0}+b_{1}\right) K \downarrow$

where $b_{0}$ and $b_{1}$ are estimates of the regression constants. This empirical model has shown excellent linearity in all studies that have been conducted. The relationship expressed by Eq. (10), particularly for cloudless skies, is statistically significant (Kaminsky and Dubayah, 1997; Alados et al., 2003). The evidence presented in these studies has contributed to the general acceptance of the use of this model.

However, as expressed by Gay (1971), there is apparent confusion as to the statistical nature of the model reported above (Eq. 10) and an apparent failure to clearly recognize the relationship between the empirical model and the actual process of radiation exchange. One alternative is to model the relationship of net radiation as it varies with transfer coefficient long wavelength $(\lambda)$, which is based on the dependence of $L^{*}$ (net flux longwave) on $K \downarrow$. In the new proposed model (enhanced), $L^{*}$ is identified as the dependent variable and consists of two components, $L \downarrow$ and $L \uparrow$. Such a model is then proposed as:

$$
Q^{*}=(1+\lambda) K^{*}+L^{*}
$$

wherein $K^{*}=K \downarrow-K \uparrow$ and $L^{*}{ }_{0}$ is the statistical estimate of $L^{*}$ when $K \downarrow=0$. The case of $\lambda$ is defined by the following equation:

$\lambda=\left(L^{*}-b_{1}\right) / K^{*}$

The characteristics of the radiation exchange of a natural surface are described by a single regression model if the longwave radiation emitted by the surface $(L \uparrow)$ has a definable relationship when returned to the atmosphere $(L \downarrow)$. 
Table I. Mean values of radiation balance components in different surface types.

The $Q_{\text {ext }}$ value is also presented. All values are in $\mathrm{Wm}^{-2}$.

\begin{tabular}{lccccc}
\hline Date & $\begin{array}{c}08 / 06 / 2011 \\
\text { Clay }\end{array}$ & $\begin{array}{c}08 / 10 / 2011 \\
\text { Asphalt }\end{array}$ & $\begin{array}{c}08 / 13 / 2011 \\
\text { Concrete }\end{array}$ & $\begin{array}{c}08 / 19 / 2011 \\
\text { PWEP }\end{array}$ & $\begin{array}{c}\text { 08/25/2011 } \\
\text { Grass }\end{array}$ \\
\hline$Q_{\text {ext }}$ & 449.9 & 445.0 & 441.0 & 432.2 & 422.3 \\
$K \downarrow$ & 340.6 & 314.1 & 314.0 & 303.2 & 289.5 \\
$K \uparrow$ & -79.9 & -44.9 & -78.3 & -199.4 & -65.5 \\
$L \downarrow$ & 399.3 & 434.7 & 434.3 & 443.1 & 459.3 \\
$L \uparrow$ & -546.5 & -554.8 & -544.1 & -512.0 & -522.6 \\
$Q^{*}$ & 113.6 & 146.1 & 123.4 & 33.6 & 159.0 \\
\hline
\end{tabular}

\section{Results and discussion}

\subsection{Radiation balance}

The average values of the radiation balance components for experimental surfaces are shown in Table I; the expected accuracy is of $\pm 10 \%$ according to the manufacturer's specifications (Hukseflux Thermal Sensors). Because the measurements were performed on different days, the values of $Q_{\text {ext }}, K \downarrow$ and $L \downarrow$ have differing starting values. However, when performing a $t$-test, the mean difference (with a significance level of 0.05 ) between the values of $Q_{e x t}$ and $K \downarrow$ indicates no significant statistical difference. Measurements of $L \downarrow$ exhibited no significant difference in the measurements of asphalt, concrete, and PWEP. However, differences did exist between grass and clay. Measurements were taken during clear days, which imply that factors such as water vapor content and atmospheric aerosols could have contributed to the differences.

The radiation balance of each surface is presented in Figures 2 to 6 . These figures show that the daily patterns of $Q_{e x t}, K \downarrow$, and $Q^{*}$ exhibit similar behavior, with the highest values at solar noon for most surfaces. However, PWEP surfaces differ with respect to the other materials in terms of $Q^{*}$, both by smallest size and the time delay in its maximum value. Reflected shortwave radiation $K \uparrow$, being a function of albedo $(\alpha)$, shows a diurnal behavior dependent on the underlying surface and the angle of inclination of the solar rays. Longwave downwelling and upwelling radiation, $L \uparrow$ and $L \downarrow$, respectively, do not show the characteristic waveform of the other fluxes and display slightly more variation in $L \uparrow$.

\subsection{Biophysical properties}

Figure 7 shows the variability of albedo $(\alpha)$ from the surfaces, ranging from 0.12 to 0.82 ; asphalt, with an average value of 0.19 , has the lowest value, whereas the highest average value, PWEP, is 0.69. Thus, asphalt is one of the main contributors to a warmer thermal environment because it stores

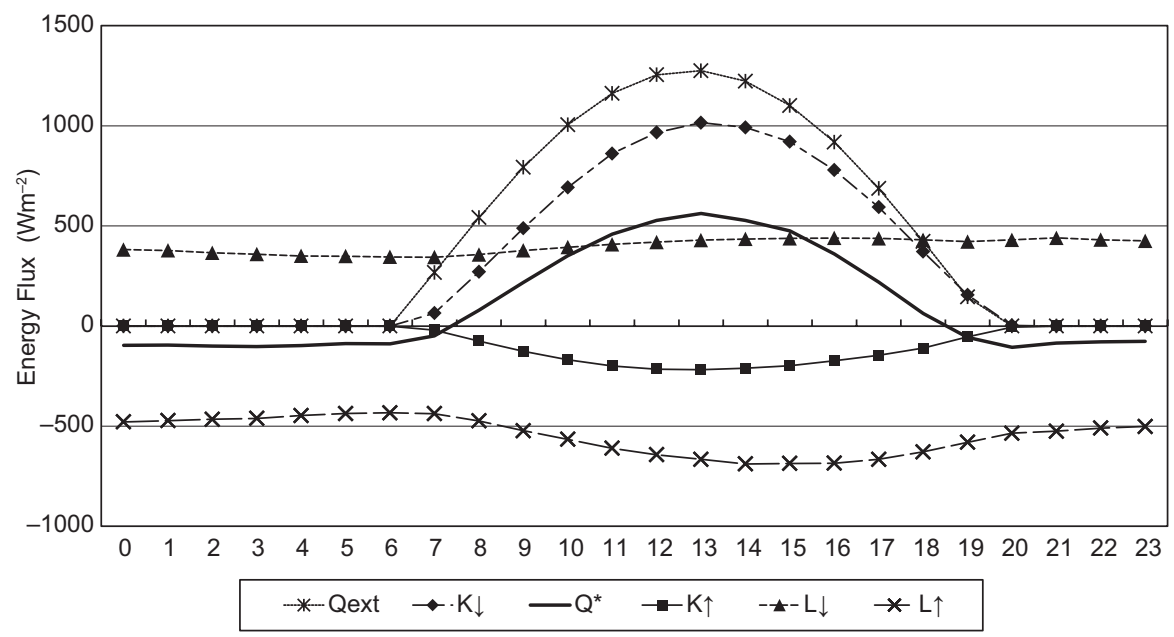

Fig. 2. Radiation balance on clay surface at Mexicali, Mexico, for August 6, 2011. 


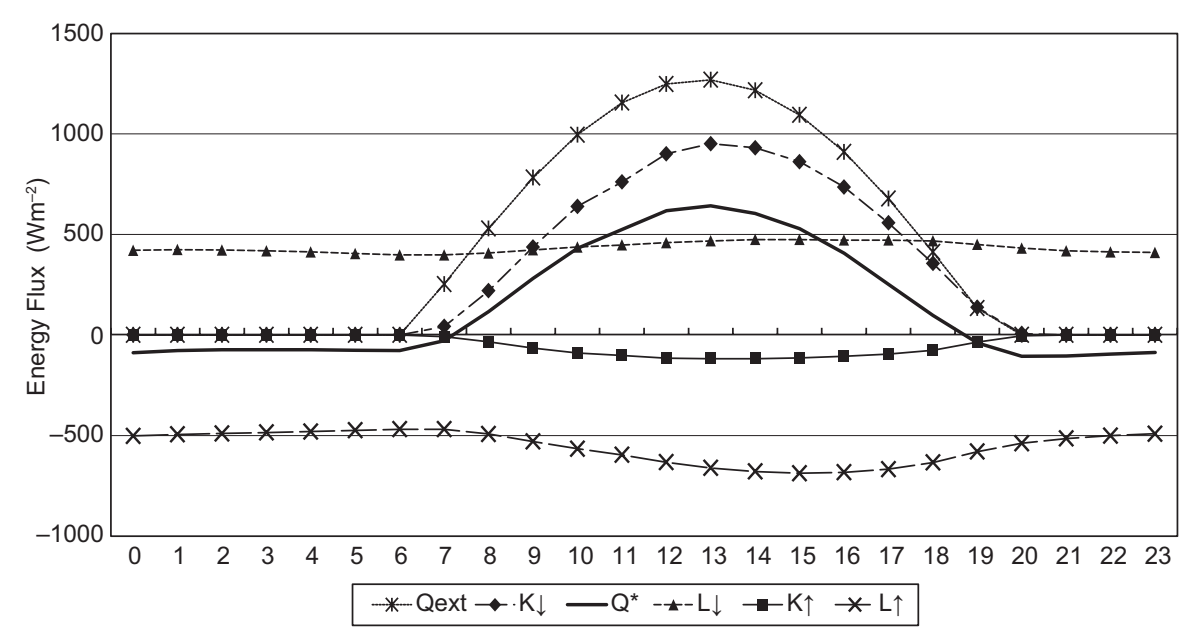

Fig. 3. Radiation balance on an asphalt surface at Mexicali, Mexico, for August 8, 2011.

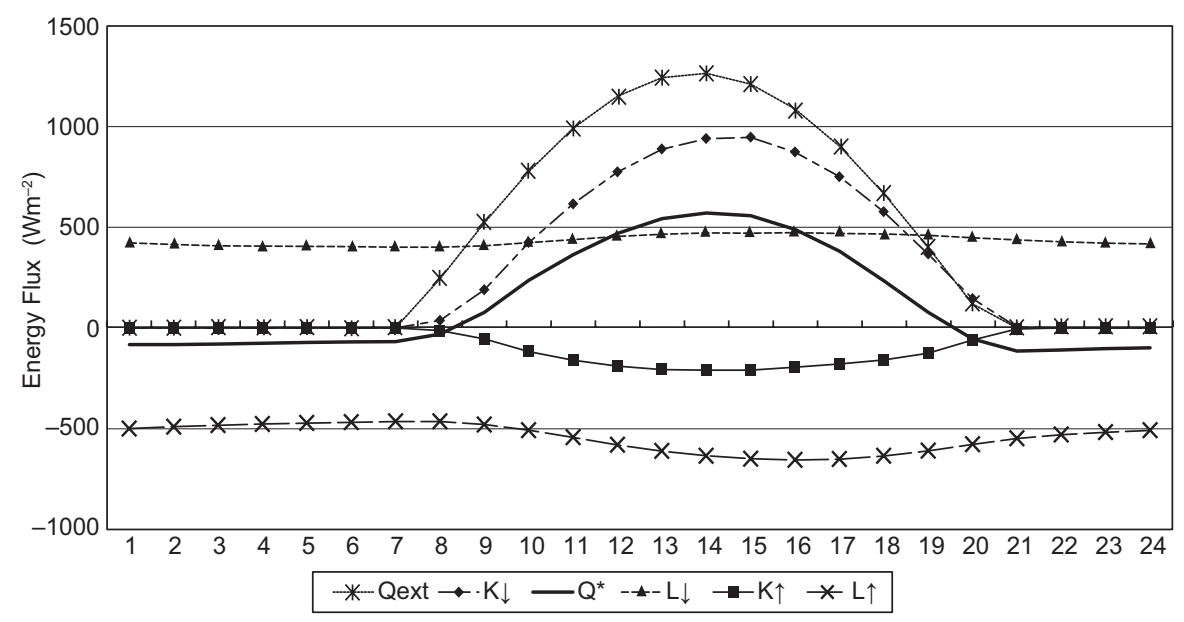

Fig. 4. Radiation balance on a concrete surface at Mexicali, Mexico, for August 13, 2011.

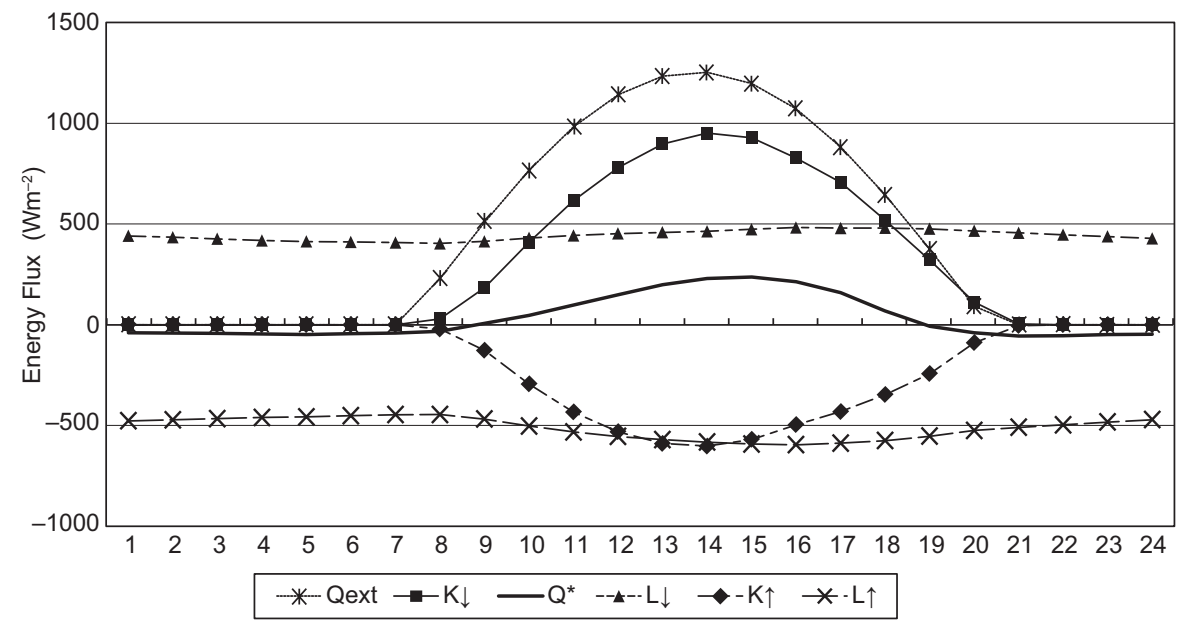

Fig. 5. Radiation balance on a PWEP surface at Mexicali, Mexico, for August 19, 2011. 


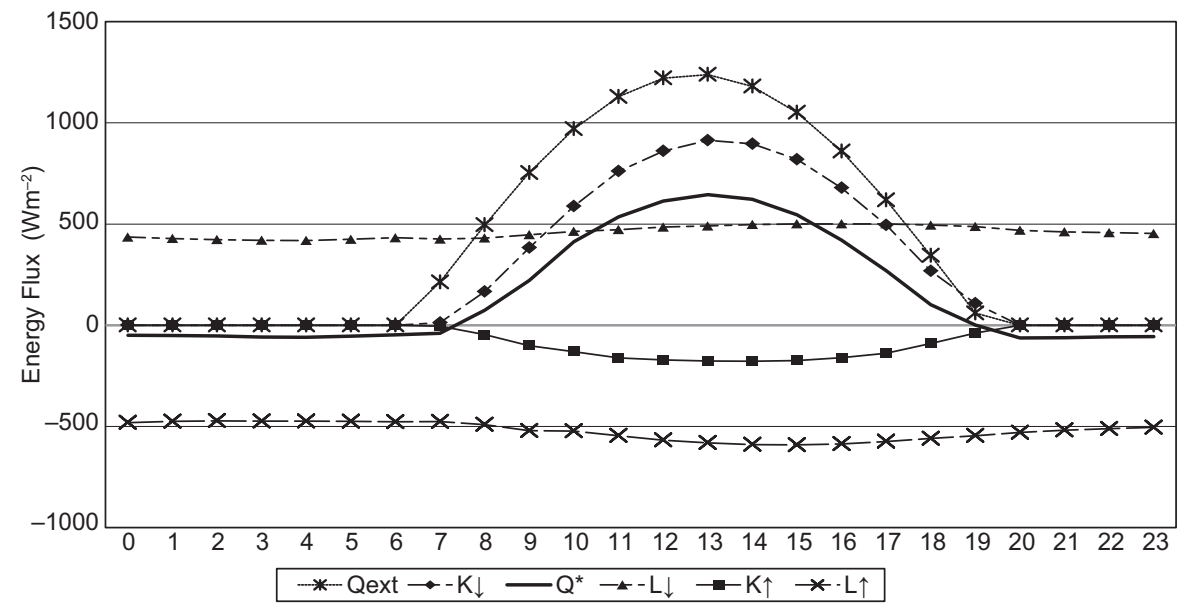

Fig. 6. Radiation balance on grass surface at Mexicali, Mexico, for August 25, 2011.

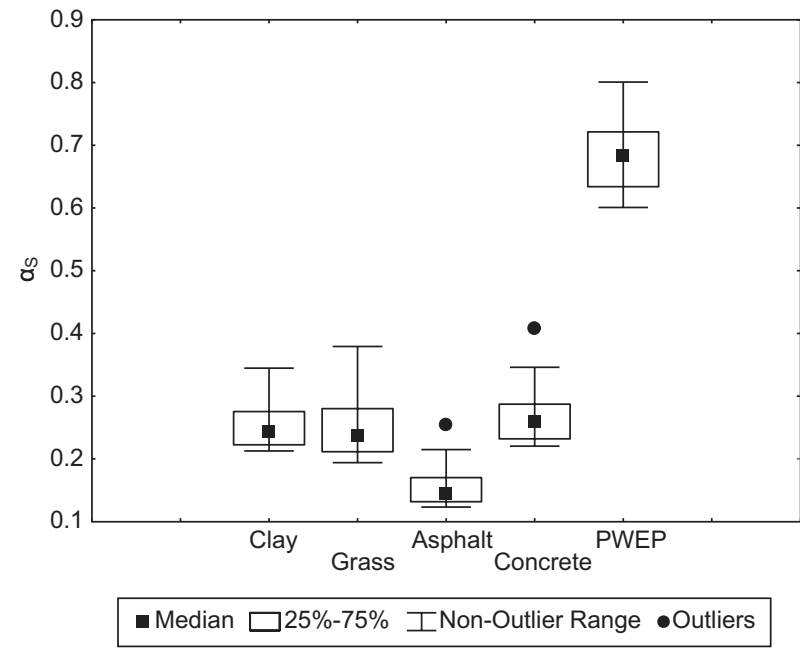

Fig. 7. Variability of albedo over different surfaces at Mexicali, Mexico in August 2011.

more incoming solar radiation and reflects less. Conversely, PWEP reflects more shortwave radiation, resulting in less environmental impact on its surroundings. Clay, concrete, and grass had albedos comparable to each other at $0.25,0.27$, and 0.26 , respectively.

Atmospheric emissivity $\left(\varepsilon_{a t m}\right)$, which is shown in Figure 8, exhibited the lowest estimated value for clay with 0.78 . The other surfaces had emissivity values between 0.85 and 0.86 . Because emissivity is dependent on incoming longwave radiation and air temperature, which in turn are dependent on water vapor and aerosols, we can infer that measurements were made on similar days.

The atmospheric clearness index had a range

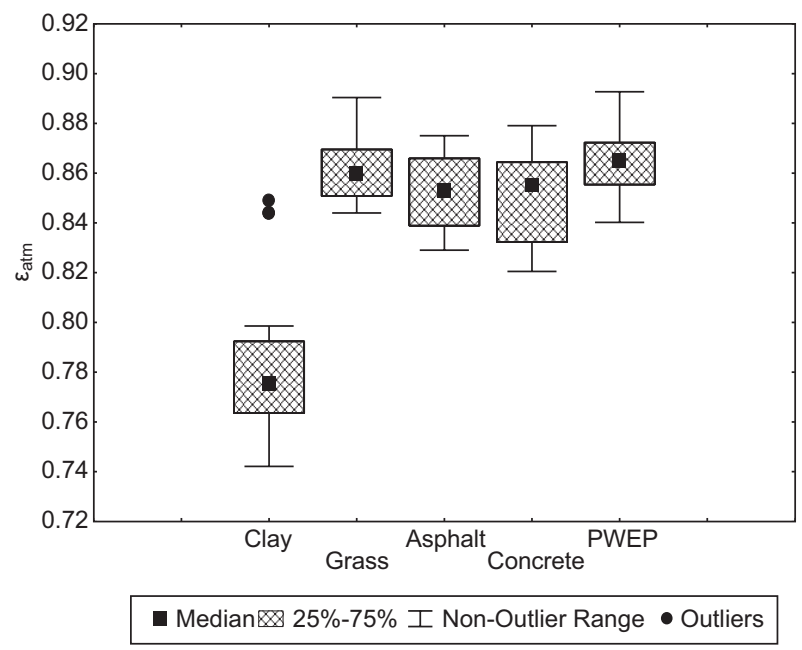

Fig. 8. Variability of atmospheric emissivity over different surfaces at Mexicali, Mexico in August 2011.

between 0.69 and 0.73 , with the lowest value for asphalt and the highest for clay (Fig. 9). These values are not dependent on the surface coverage but rather indicate that on average, $30 \%$ of the energy arriving at the top of the atmosphere is dissipated before reaching the measured surface. Comparisons with research conducted in Bogotá show that Mexicali has a more transparent atmosphere on clear days, as the average value of atmospheric clearness index in Bogotá was estimated at 0.663 (Forero et al., 2008). Another study, focusing on the central and southern arid coastal zones over the Peruvian Andes, found that the minimum and maximum values of atmospheric transmissivity varied between 0.3 and 0.8 (Baigorria et al., 2004). 


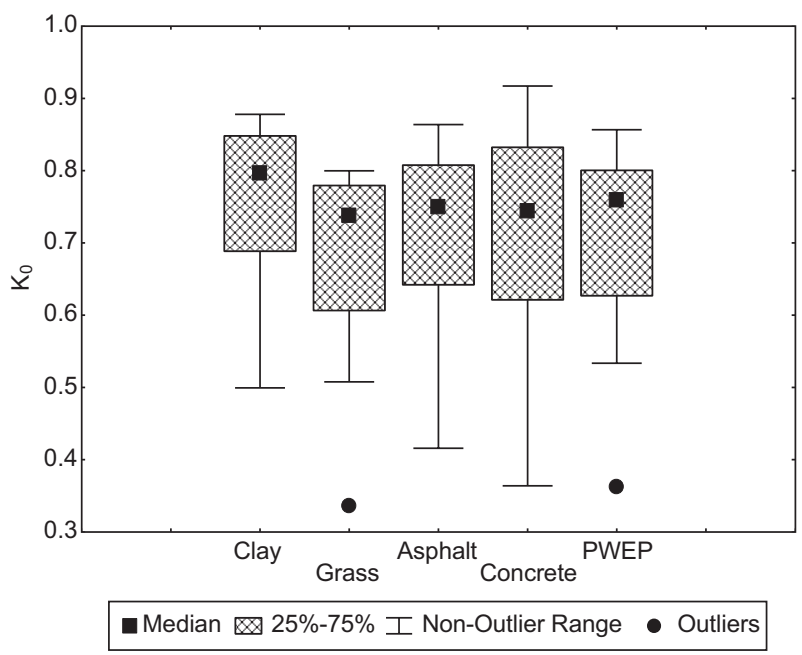

Fig. 9. Index of atmospheric clearness at Mexicali, Mexico in August 2011.

\subsection{Preliminary net radiation models}

Models based on Eq. (10) have demonstrated excellent linearity and statistical robustness in all studies that have been carried out, particularly for a clear sky. It was necessary to apply the Durbin-Watson test to ensure that residuals are not correlated, but it was found that no model passed the test, so the Cochran-Orcutt transformation was used for the response variable and the predictor variable for each one of the studied surfaces. It was found again that it was impossible to reject the null hypothesis of zero autocorrelation, so it will be necessary to seek an autoregressive moving average model type in a later study. This fact does not invalidate the proposed models; however, the mean square error may underestimate the residual variance, and the standard deviation of the estimated regression coefficient may be lower than the actual standard deviation. Because the confidence intervals and tests using the $t$ and $F$ distribution are no longer strictly applicable, the coefficient of determination $\left(R^{2}\right)$, the standard errors of the regression parameters and the root mean square error $(\sqrt{E} E M)$ are used as indicators of the quality of models (Table II).

The models based on Eq. (11), which depend on the measurement surface and prevailing weather conditions, are presented in Table III. The $R^{2}$ values for these models are not significantly different from the first proposal (Eq. 10), except for PWEP, where net radiation is $99 \%$ instead of $97 \%$.

This model assumes that radiative equilibrium exists between the surface and the atmosphere, so no advection occurred during the observations. Atmospheric properties have some effect on $L \downarrow$ and, consequently, on $L^{*}$. Because $L \downarrow$ is generally more

Table II. Linear models to estimate net radiation $\left(Q^{*}\right)$ as a function of downwelling shortwave radiation $(K \downarrow) . \sqrt{ } E C M$ is the root mean square error; $R^{2}$ is the coefficient of determination.

\begin{tabular}{lcccc}
\hline Surface type & $b_{0}$ & $b_{1}$ & $\sqrt{ } E C M$ & $R^{2}$ \\
\hline Clay & $-101.3(6.8)$ & $0.63(0.01)$ & 25.4 & 0.99 \\
Asphalt & $-88.8(9.9)$ & $0.75(0.02)$ & 37.0 & 0.99 \\
Concrete & $-90.8(9.5)$ & $0.68(0.02)$ & 35.6 & 0.99 \\
PWEP & $-52.3(4.8)$ & $0.28(0.01)$ & 18.2 & 0.97 \\
Grass & $-60.0(3.7)$ & $0.76(0.01)$ & 14.1 & 0.99 \\
\hline
\end{tabular}

Table III. Linear models to estimate net radiation $\left(Q^{*}\right)$ as a function of net shortwave radiation $\left(K^{*}\right)$. $\sqrt{E C M}$ is the root mean square error; $R^{2}$ is the determination coefficient; $\lambda$ is the exchange coefficient longwave; $\alpha$ is the surface albedo; $T_{S U R F}$ is the average surface temperature, and $T_{M X S U R F}$ is the maximum surface temperature.

\begin{tabular}{llcccccc}
\hline Surface type & \multicolumn{1}{c}{ Model } & $\sqrt{ } E C M$ & $R^{2}$ & $\lambda$ & $\alpha$ & $T_{\text {SURF }}$ & $T_{\text {MXSURF }}$ \\
\hline Clay & $Q^{*}=0.81 K^{*}-102.0$ & 22.3 & 0.99 & -0.19 & 0.25 & 39.9 & 65.2 \\
Asphalt & $Q^{*}=0.86 K^{*}-85.2$ & 25.1 & 0.99 & -0.14 & 0.19 & 42.2 & 63.5 \\
Concrete & $Q^{*}=0.89 K^{*}-85.4$ & 25.1 & 0.99 & -0.11 & 0.27 & 39.7 & 58.8 \\
PWEP & $Q^{*}=0.79 K^{*}-48.0$ & 6.3 & 0.99 & -0.21 & 0.69 & 33.3 & 46.3 \\
Grass & $Q^{*}=0.96 K^{*}-54.9$ & 6.0 & 0.99 & -0.05 & 0.26 & 34.7 & 44.5 \\
\hline
\end{tabular}


stable than $L \uparrow$, which can be determined by observing the radiation balance, the effects of the different surfaces analyzed in this research are emphasized.

Note that all values of $\lambda$ are negative, implying that surfaces convert solar energy absorbed mostly into sensible heat (Gay, 1971). It can be observed that the value of $\lambda$ for grass is close to zero, implying that part of the energy is also being used for evapotranspiration. Of the measured experimental data, an inverse relationship between the surface temperature $\left(T_{\text {SURF }}\right)$ and albedo $(\alpha)$ (Table III) was observed.

Higher average temperatures were observed for surfaces with the lowest albedo, and lower temperatures for surfaces with higher albedos. For grass surfaces, the heat spent in evapotranspiration processes causes the temperature to be lower than in surfaces with similar albedos, such as clay or concrete. One important difference in the two models proposed is the empirical slope of all observed surfaces. We discuss two different surfaces, asphalt and grass, which have similar slopes ( 0.75 and 0.76 , respectively; see Table II). The differences in radiation balance are due to differences in albedo and energy use, 0.19 and 0.26 , respectively, as mentioned above. The difference of the slope in the two models is significant. For example, for PWEP, the empirical model (Eq. 10) shows that if the surface absorbs $1.0 \mathrm{Wm}^{-2}$ of incoming solar radiation $(K \downarrow)$, the net radiation would increase by $0.28 \mathrm{Wm}^{-2}$. However, the enhanced model (Eq. 11) would increase by $0.79 \mathrm{Wm}^{-2}$. Therefore, the latter model shows that the response model is affected by both the surface and the albedo. Also significant is that this model has found the net longwave radiation $\left(L^{*}\right)$ to be the independent variable.
To give statistical robustness to the proposal of preliminary net radiation models with respect to the independence of measurements realized, a comparison between the net radiation estimated with the NR01 radiometer and the net radiation measured with the $\mathrm{Q}^{*}$ 7.1 radiometer was performed, which is shown in Figure 10. The number of data used was 120. It is observed that there is a linear relationship between these two variables, with a correlation coefficient of 0.98 . This indicates that the components of short-wave radiation and longwave radiation can be used to estimate the net radiation with sufficient accuracy, regardless of the sensor used. At this point, it must be remembered that the models were obtained on cloudless days, which has as consequence that the determination coefficients were substantially high, as in the studies mentioned in section 2.3.4.

\subsection{Urban implications}

The types of surfaces that most affect human thermal comfort are asphalt and concrete because their effects are felt by pedestrians. These surfaces had the lowest albedos of all analyzed coverage surface. According to the Instituto Municipal de Investigación y Planeación Urbana de Mexicali (Municipal Institute for Research and Urban Planning of Mexicali) (IMIP, 2010), asphalt and concrete are in a proportion of approximately $20 \%$ in the urban land uses in Mexicali. Because of their physical properties (high heat capacity and low albedo), these materials are responsible for the generation of an urban heat island, as has been shown in other studies (García Codrón et al., 2004; Bo et al., 2012).

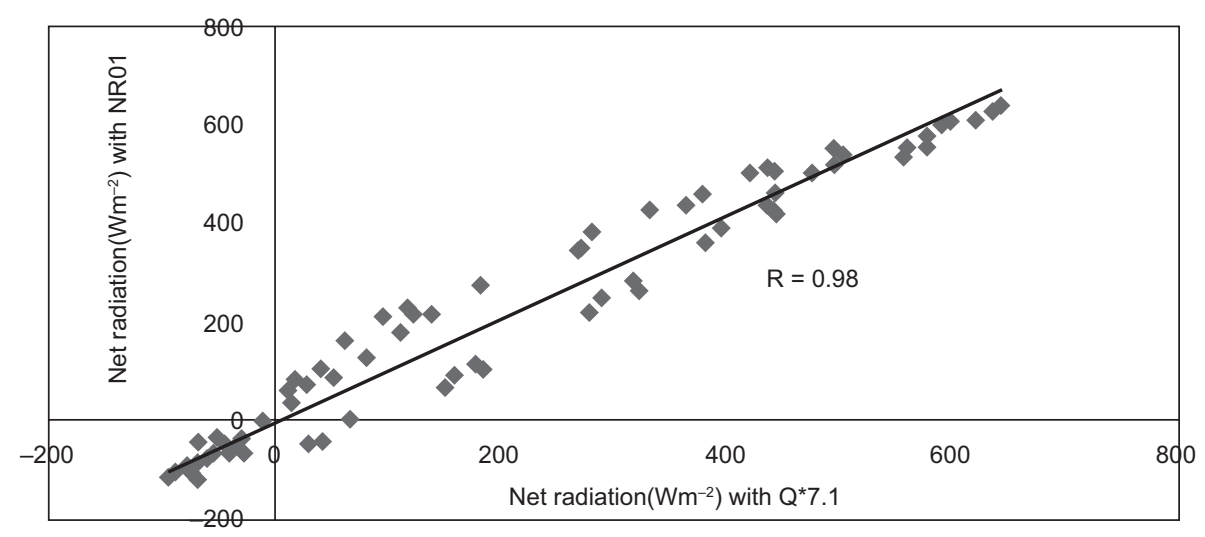

Fig. 10. Net radiation: Q*7.1 vs. NR01, Mexicali, Mexico, August 2011. 


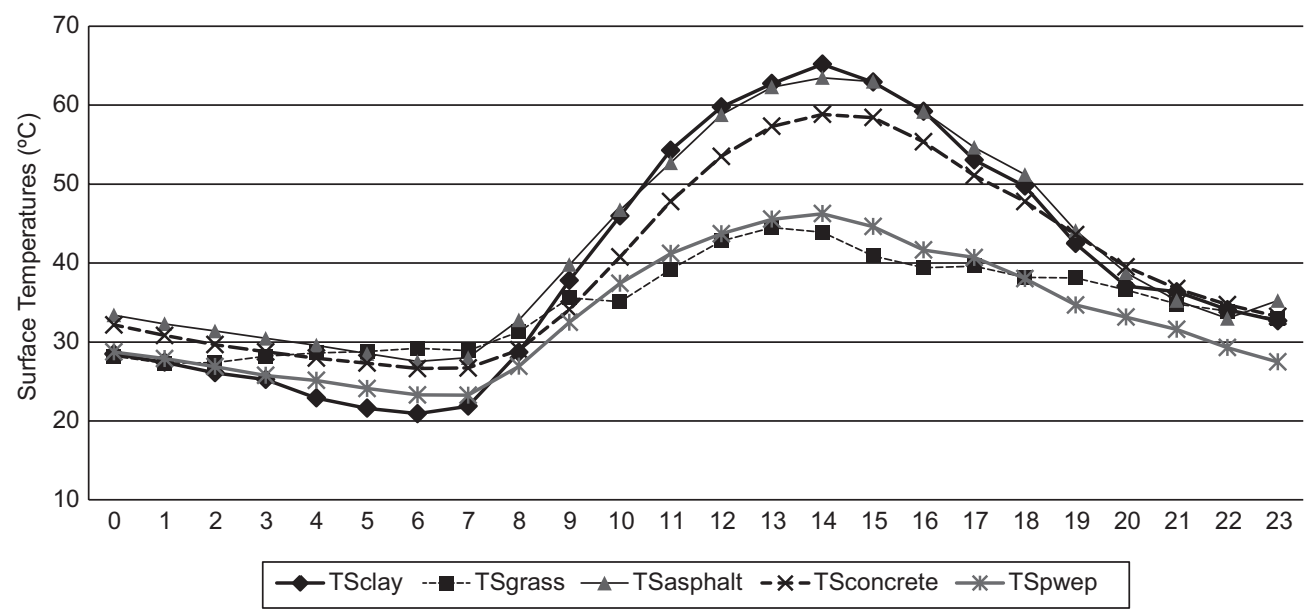

Fig. 11. Mean diurnal surface temperatures at Mexicali, Mexico in August 2011.

The high albedo of PWEP substantially reduces the net radiation, leaving less energy available in the surface for sensible heating of the air during the day, which could provide an efficient mitigation of the urban heat island and energy savings in the consumption of buildings through the use of cool roofs (Coutts et al., 2013; Radhi, 2014). In Mexicali, PWEP is used on the roofs of buildings; however, there is no quantification of the amount of this material being utilized for that purpose. According to the IMIP (2010), 56\% of the surface of Mexicali is for residential use; however, not all of this percentage pertains to roofing constructions and not all housing developments use PWEP in their rooftops, which could be highly beneficial if this material became the norm for the construction of rooftops for houses and garages in the future.

Additionally, there is a portion of land that is not accounted for when discussing land use in Mexicali, although it is an important part of the urban area. This large, non-urbanized, vacant portion of land of 2973 ha (i.e., $14 \%$ of the surface of Mexicali) is formed by clay (the native soil of the region) with an albedo very similar to that of concrete and grass, and it greatly contributes not only to the intense daytime heating (similar to that of asphalt) but also to the rapid cooling at night (Fig. 11). The thermal contrast between native soil (clay) and urban coverages (asphalt and concrete) has been suggested by other studies (García-Cueto et al., 2009; Casillas et al., 2014) as one of the causes of the heat island in Mexicali, which is typically a nocturnal phenomenon.

It can be seen from the above comments that this research lacks a detailed analysis of the amount of each type of coverage surface discussed citywide; therefore, a pending study is needed to estimate the spatial coverage of each surface using remote sensing and geographic information systems.

In order of numerical importance, the upward longwave radiation $(L \uparrow)$ in the materials analyzed (see Table I) are asphalt, concrete, and PWEP. Asphalt and concrete can increase the thermal load on pedestrians, causing great thermal discomfort. Grass surfaces, although with an albedo very similar to that of concrete, exhibited lower temperatures (on average $5{ }^{\circ} \mathrm{C}$ lower) because of the evapotranspiration process. This observation could be used in urban planning through the use of materials that allow the free exchange of water between them and the underlying soil, such as a porous materials with low density and low heat capacity.

The emissivity and clearness indices of the local atmosphere mean that the atmospheric transparency of Mexicali results in high net solar radiation. The management of the resulting thermal load on the exposed population would ideally be done by using surfaces with high albedo (such as PWEP) and humidity (such as grass, due to the evapotranspirative process) to diminish surface temperatures. Further research to analyze the importance of native vegetation in achieving a sustainable environment would still be necessary.

This analysis only considers cloudless conditions over a 24-h period for each surface type in a typical summer month in Mexicali. Further work is planned to continue analyzing radiative balance over longer periods of time in different weather conditions to 
gain a better understanding of seasonal behavior and further corroborate our current findings.

Both preliminary models used in this study gave good results. However, we chose the enhanced model due to the improved physics, the smallest standard error of the regression parameters, and determination coefficients, resulting in more accurate estimates.

\section{Conclusions}

In our analysis of radiative balance, it was observed that net radiation is different depending on the surface type at which it is measured. For a 24-h period over five days in August 2011, the highest average value for net radiation was $146.1 \mathrm{Wm}^{-2}$ for an asphalt surface. The average net radiation value was 33.6 $\mathrm{Wm}^{-2}$ for PWEP. This difference is primarily due to the albedo of each surface, as atmospheric emissivity and atmospheric clearness index had similar values. PWEP had the highest albedo, with a value of 0.69 , and asphalt had the lowest, at 0.19 . Therefore, asphalt is one of the main factors responsible for a warmer thermal environment because it stores more downwelling shortwave radiation and reflects less. Because PWEP reflects more incoming solar radiation (approximately 70\%), it produces less sensible heat to warm the surrounding environment, which could provide an efficient mitigation of the urban heat island and savings in the energy consumption of buildings. Grass, which has a similar albedo to concrete and clay, uses some of its energy for evapotranspiration; thus, it exhibited the lowest maximum temperature of the five coverage surfaces studied. Estimates of net radiation in both preliminary models resulted in coefficients of determination greater than 0.97 , but the enhanced model is recommended by the authors of this study due to the physical parameters involved in its design. We recommend further study to conduct accurate measurements for the entire city and allow for economically viable bio-urbanistic planning.

\section{References}

Alados I., I. Foyo-Moreno, F. J. Olmo and L. Alados-Arboledas, 2003. Relationship between net radiation and solar radiation for semi-arid shrub-land. Agr. For. Meteorol. 116, 221-227.

Anthoni P. M., Law B. E., Unsworth M. H. and Vong R. J., 2000. Variation of net radiation over heterogeneous surfaces: measurements and simulation in a juniper-sagebrush ecosystem. Agr. For. Meteorol. 102, 275-286.

Arnfield A. J., 2003. Two decades of urban climate research, exchanges of energy and water, and the urban heat island. Int. J. Climatol. 23, 1-26.

Ayoola A. M., L. A. Sunmonu, M. I. Bashiru and O. O. Jegede, 2014. Measurements of net all-wave radiation at a tropical location, Ile-Ife, Nigeria. Atmósfera 27, 305-315.

Baigorria G. A., E. B. Villegas, I. Trebejo, J. F. Carlos and R. Quiroz, 2004. Atmospheric transmissivity: Distribution and empirical estimation around the central Andes. Int. J. Climatol. 24, 1121-1136.

Bennie B. H. J., A. Wiltshire, M. O. Hill and R. Baxter, 2008. Slope, aspect and climate: Spatially explicit and implicit models of topographic microclimate in chalk grassland. Ecol. Model. 216, 47-59.

Bo H., W. Yuesi and L. Guangren, 2012. Relationship between net radiation and broadband solar radiation in the Tibetan plateau. Adv. Atmos. Sci. 29, 135-143.

Casillas H. A., O. R. García-Cueto, O. C. Leyva and F. F. N. González, 2014. Detección de la isla urbana de calor mediante modelación dinámica: caso Mexicali, México. Inf. Tecnol. 25, 139-150, doi:10.4067/S071807642014000100015.

Colliber D. G., 1991. Techniques of estimating incident solar radiation. In: Solar energy in agriculture (B. F. Parker, Ed.). Elsevier, Amsterdam, pp. 1-66.

Coutts A. M., E. Daly, J. Beringer and N. Tapper, 2013. Assessing practical measures to reduce urban heat: Green and cool roofs. Build. Environ. 70, 266-276.

Cui Y. P., Y. J. Liu and Y. F. Hu, 2012. Modeling the radiation balance of different urban underlying surfaces. Chinese Sci. Bull. 57, 1046-1054, doi:10.1007/ s11434-011-4933-x.

Christen A and R. Voogt, 2004. Energy and radiation balance of a central European city. Int. J. Climatol. 24, 1395-1421.

Forero N. L., W. Meza, M. A. Martínez, L. M. Caicedo and G. Gordillo, 2008. Estimación del valor medio mensual del índice de claridad atmosférico (Kt) para Bogotá, a partir de datos de radiación solar global. Rev. Colom. Fis. 40, 167-169.

García Codrón J. C., C. Diego Liaño, H. P. Fernández de Arróyabe, C. Garmendia Pegraja and D. Rasilla Álvarez, 2004. El clima entre el mar y la montaña. Asociación Española de Climatología y Universidad de Cantabria, Santander (Serie A, 4). 
García-Cueto O. R., A. Tejeda-Martínez and G. Bojórquez-Morales, 2009. Urbanization effects upon the air temperature in Mexicali, B. C., Mexico. Atmósfera 22, 349-365.

García-Cueto O. R. and N. Santillán-Soto, 2012. Modeling extreme climate events: Two case studies in Mexico. In: Climate models (L. M. Druyan, Ed.). Intech, Croatia, pp. 137-160.

Geraldo-Ferreira A., E. Soria-Olivas, J. Gómez-Sanchís, A. J. Serrano-López, A. Velázquez-Blázquez and E. López-Baeza, 2011. Modelling net radiation at surface using "in situ" net pyrradiometer measurements with artificial neural networks. Expert Syst. Appl. 38, 14190-14195.

Groleau D. and G. P. Mestayer, 2013. Urban morphology influence on urban albedo: A revisit with the SOLENE model. Bound.-Lay. Meteorol. 147, 301-327.

IMIP, 2010. Plan maestro de vialidad y transporte de Mexicali, B.C. Usos del suelo área urbana. Instituto Municipal de Investigación y Planeación Urbana de Mexicali, Gobierno Municipal de Mexicali. Available at: imipmexicali.org.mx (last accessed on October 27, 2014).

Iqbal M., 1983. An introduction to solar radiation. Academic Press, New York, 390 pp.

Ji X., E. Kang, W. Zhao, Z. Zhang and B. Jin, 2009. Simulation of heat and water transfer in a surface irrigated, cropped sandy soil. Agr. Water Manage. 96, 1010-1020.

Kalthoff N., M. Fiebig-Wittmaack, C. Meißner, M. Kohler, M. Uriarte, I. Bischoff-Gauß and E. González, 2006. The energy balance, evapo-transpiration and nocturnal dew deposition of an arid valley in the Andes. J. Arid Environ. 65, 420-443.

Kaminsky K. Z. and R. Dubayah, 1997. Estimation of surface net radiation in the boreal forest and northern prairie from shortwave flux measurements. J. Geophys. Res. 102, 29707-29716.

Kessler A. and L. Jaeger, 1999. Long-term changes in net radiation and its components above a pine forest and grass surface in Germany. Int. J. Climatol. 19, 211-226.

Kumar R. and L. Umanand, 2005. Estimation of global radiation using clearness index model for sizing photovoltaic system. Renew. Energ. 30, 2221-2233.

Li S., L. Tong, F. Li, L. Zhang, B. Zhang and S. Kang, 2009. Variability in energy partitioning and resistance parameters for a vineyard in northwest china. Agr. Water Manage. 96, 955-962.

Offerle B., C. S. B. Grimmond and T. R. Oke, 2003. Parameterization of net all wave radiation for urban areas. J. Appl. Meteorol. 42, 1157-1173.

Radhi H., E. Assem and S. Sharples, 2014. On the colours and properties of building surface materials to mitigate urban heat islands in highly productive solar regions. Build. Environ. 72, 162-172.

Schmid H. P, 1997. Experimental design for flux measurements: Matching scales of observations and fluxes. Agric. For. Meteorol. 87, 179-200.

Wang X. Q. and Y. B. Gong, 2010. The impact of an urban dry island on the summer heat wave and sultry weather in Beijing City. Chinese Sci. Bull. 55, 1657-1661.

White J. M., F. D. Eaton and A. H. Auer, 1978. The net radiation budget of the St. Louis metropolitan area. J. Appl. Meteorol. 17, 593-599. 